\title{
DISPONIBILIDADE DE MACRONUTRIENTES EM Eucalyptus saligna CULTIVADOS COM LODO DE PAPEL RECICLADO
}

\author{
Álvaro Boson de Castro Faria ${ }^{1}$, Alessandro Camargo Angelo ${ }^{2}$, Celso Garcia Auer $^{3}$ \\ ${ }^{1}$ Universidade Tecnológica Federal do Paraná, Dois Vizinhos, Paraná, Brasil - alvarob@utfpr.edu.br \\ ${ }^{2}$ Universidade Federal do Paraná, Curitiba, Paraná, Brasil - alessandrocangelo@ gmail.com \\ ${ }^{3}$ Empresa Brasileira de Pesquisa Agropecuária, Colombo, Paraná, Brasil - celso.auer@embrapa.br \\ Recebido para publicação: 10/04/2012 - Aceito para publicação: 10/09/2014
}

\begin{abstract}
Resumo
Os resíduos sólidos da indústria de reciclagem de papel têm potencial de uso para correção da acidez do solo e como fonte de nutrientes para as culturas agrícolas e florestais. Este trabalho teve como objetivo avaliar os efeitos de diferentes doses de lodo de papel reciclado e de adubação de cobertura sobre a disponibilidade de macronutrientes em Eucalyptus saligna Smith, com base em um ensaio com mudas com três meses de idade transplantadas para vasos distribuídos com espaçamento em uma área experimental. Após a homogeneização da granulometria e da umidade do lodo, foi implantado um delineamento inteiramente casualizado com dois fatores (dose e adubação em cobertura) e três repetições, totalizando dezoito amostras de folhas e dezoito de raízes por micronutriente. O lodo de papel reciclado não interferiu na disponibilização do P. Também não foi uma fonte de $\mathrm{N}, \mathrm{K} \mathrm{e} \mathrm{Mg}$ para as plantas. O resíduo foi uma fonte de Ca para o desenvolvimento vegetal.

Palavras chave: Produção florestal; resíduos agroindustriais; sustentabilidade.
\end{abstract}

\begin{abstract}
Macronutrients availability in Eucalyptus saligna grown with recycled paper sludge. The solid waste of recycling paper industry has potential to be used for the correction of soil acidity and as a source of nutrients for agricultural crops and forestry. This work aimed to evaluate the effects of different doses of recycled paper sludge and top fertilization on the availability of macronutrients in Eucalyptus saligna Smith, based on a test with seedlings with three months old transplanted to pots distributed with spacing an experimental area. After homogenization of particle size and moisture content of the sludge, was implemented a completely randomized design with two factors (dose and top fertilization), and three repetitions, totaling eighteen samples of leaves and roots for each micronutrient. The recycled paper sludge did not affect the availability of P. Also, did not was a source of $\mathrm{N}, \mathrm{K}$, and $\mathrm{Mg}$ for plants. The residue was a source of $\mathrm{Ca}$ for the vegetal development. Keywords: Forestry; agro-industrial residues; sustainability.
\end{abstract}

\section{INTRODUÇÃO}

As indústrias de papel e celulose geram poluição ambiental (STAPPE; BALLONI, 1988; GONÇALVES; MORO, 1995). Os constantes aumentos na demanda de produção implicam a geração diária de grande quantidade de resíduos, em função dos diferentes processos tecnológicos e da qualidade das aparas de papel, constituindo uma preocupação ambiental. Da mesma forma, a indústria de papel reciclado também gera passivos ambientais na forma de resíduos sólidos, denominados de lodo de Estação de Tratamento e Efluentes (ETE) ou lodo de papel reciclado. Autores como Andrade et al. (2005) e Rocha et al. (2004) entendem que o lodo de ETE também pode ser conceituado como biossólido.

Desde a década de 1990, a Embrapa Florestas vem dando atenção para pesquisas com cinza de caldeira e resíduo celulósico (FERREIRA et al., 1995; ANDRADE et al., 2003). Autores como Lunardi Neto et al. (2008) e Costa et al. (2009) destacam que o lodo de papel e de papel reciclado são ricos em óxidos de $\mathrm{Ca}$ e $\mathrm{Mg}$ e têm potencial para uso como corretivo de solos. Essas características tornam-se interessantes para serem aproveitadas em culturas implantadas em solos com baixa fertilidade e/ou elevada acidez, como os solos do cerrado brasileiro, ou mesmo para melhorar as propriedades físicas e

FLORESTA, Curitiba, PR, v. 45, n. 2, p. 261 - 272, abr. / jun. 2015.

Faria, A. B. de C.; Angelo, A. C.; Auer, C. G.

ISSN eletrônico 1982-4688 / ISSN impresso 0015-3826

DOI: $10.5380 /$ rf.v45i2.26506 
químicas de solos degradados (BALBINOT JÚNIOR, 2006; GALBIATTI et al., 2007; LUNARDI NETO et al., 2008; LIMA et al., 2010). Andrade et al. (2003) consideram viável a utilização de resíduos de fábricas de papel e celulose em plantios de eucalipto.

O presente trabalho parte do princípio de que os passivos ambientais gerados por indústrias podem ser reutilizados como insumos para a geração de produtos inovadores, contribuindo para o desenvolvimento de tecnologias mais limpas e para a geração de empregos e renda em novos mercados.

Há escassez de trabalhos sobre o uso de resíduos de reciclagem de papel para correção da acidez do solo e/ou como fonte de nutrientes para as culturas agrícolas e florestais (BALBINOT JÚNIOR et al., 2006). Corretivos de solo podem causar a redução dos teores de $\mathrm{K}^{+}$no solo e a calagem para plantações de eucalipto pode ser desaconselhável, até que se conheça a sua implicação com os demais nutrientes e com as necessidades da planta (VALERI et al., 1985). As pesquisas realizadas com resíduos da indústria de papel e celulose mostram grande expectativa de uso e aumento da produtividade do eucalipto, em consequência da melhoria das propriedades do solo.

Este trabalho teve como objetivo avaliar o efeito de lodo de papel reciclado e da adubação de cobertura na disponibilidade de macronutrientes para Eucalyptus saligna Smith com base em um ensaio com mudas em vasos distribuídos em campo.

\section{MATERIAL E MÉTODOS}

\section{Local de estudo}

$\mathrm{O}$ estudo foi realizado em área pertencente à Universidade Estadual do Centro-Oeste (UNICENTRO), no município de Irati, PR, paralelo $25^{\circ} 27^{\prime} 56^{\prime \prime}$ de latitude sul, com interseção com o meridiano 50 37'51" de longitude oeste, a $150 \mathrm{~km}$ de Curitiba. Encontra-se na região do Segundo Planalto Paranaense, com clima tipo Cfb segundo a classificação de Köppen, com geadas frequentes no inverno.

\section{Detalhes preliminares do experimento}

Foi utilizado o Latossolo de produção de mudas florestais do viveiro da universidade. Foram retiradas oito amostras aleatórias desse solo e enviadas para análise no laboratório de fertilidade do solo da Unicentro. Esse solo apresentou acidez, com baixos teores em $\mathrm{K}$ e sódio, e teores médios de $\mathrm{Ca}, \mathrm{Mg}$, Al, M.O. e P, de 3,04 $\mathrm{cmol}_{\mathrm{c}} \cdot \mathrm{dm}^{-3}, 2,14 \mathrm{cmol}_{\mathrm{c}} \cdot \mathrm{dm}^{-3}, 5,36 \mathrm{cmol}_{\mathrm{c}} \cdot \mathrm{dm}^{-3}, 40,54 \mathrm{~g} . \mathrm{dm}^{-3}$ e $8,59 \mathrm{mg} \cdot \mathrm{dm}^{-3}$, respectivamente. A saturação por bases $(\mathrm{V} \%)$ média foi de $22,4 \%$. Quanto à textura, foi considerada como sendo argilosa. Os resultados das estatísticas descritivas dos valores de caracterização físicoquímica encontram-se na tabela 1.

Tabela 1. Caracterização físico-química do solo.

Table 1. Physic and chemical characterization of the soil.

\begin{tabular}{|c|c|c|c|c|c|c|c|c|}
\hline \multirow{2}{*}{ Estatística } & \multirow{2}{*}{$\begin{array}{c}\mathrm{pH} \\
\mathrm{CaCl}_{2}\end{array}$} & $\mathbf{K}^{+}$ & $\mathrm{Ca}^{2+}$ & $\mathrm{Mg}^{2+}$ & $\mathrm{Ca}^{2+}+\mathrm{Mg}^{2+}$ & $\mathrm{Al}^{3+}$ & $\mathbf{H}^{+}+\mathbf{A l}^{3+}$ & $\mathrm{Na}^{+}$ \\
\hline & & \multicolumn{7}{|c|}{$\mathrm{cmol}_{\mathrm{c} \cdot \mathrm{dm}^{-3}}$} \\
\hline Média & 3,78 & - & 3,04 & 2,14 & 5,18 & 5,36 & 17,78 & - \\
\hline Variância & - & - & 0,48 & 0,21 & 1,13 & 0,11 & 0,66 & - \\
\hline Desvio Padrão & 0,04 & - & 0,70 & 0,46 & 1,07 & 0,33 & 0,81 & - \\
\hline Erro Padrão & 0,01 & - & 0,25 & 0,16 & 0,38 & 0,12 & 0,29 & - \\
\hline $\mathrm{CV} \%$ & 0,01 & - & 0,23 & 0,22 & 0,21 & 0,06 & 0,05 & - \\
\hline $\mathrm{IC}_{\text {MÁX }}(5 \%$ prob.) & 3,81 & - & 3,62 & 2,52 & 6,07 & 5,63 & 18,45 & - \\
\hline IC $_{\text {MÍN }}(5 \%$ prob. $)$ & 3,75 & - & 2,46 & 1,75 & 4,28 & 5,08 & 17,1 & - \\
\hline \multirow{2}{*}{ Estatística } & \multirow{2}{*}{$\begin{array}{l}\text { M.O. } \\
\text { g.dm }\end{array}$} & \multirow{2}{*}{$\begin{array}{c}P \\
\text { mg.dm }\end{array}$} & $\mathrm{V} \%$ & Areia grossa & Areia fina & Silte & Argila & \\
\hline & & & \multicolumn{4}{|c|}{ g.100g ${ }^{-1}$} & & \\
\hline Média & 40,54 & 8,59 & 22,4 & 3,75 & 2,29 & 23,21 & 70,75 & \\
\hline Variância & 58,74 & 37,19 & 0,00 & 0,42 & 0,06 & 49,36 & 54,00 & \\
\hline Desvio Padrão & 7,66 & 6,10 & 0,04 & 0,65 & 0,24 & 7,03 & 7,35 & \\
\hline Erro Padrão & 2,71 & 2,16 & 0,01 & 0,23 & 0,08 & 2,48 & 2,60 & \\
\hline $\mathrm{CV} \%$ & 0,19 & 0,71 & 16,7 & 0,17 & 0,10 & 0,30 & 0,10 & \\
\hline $\mathrm{IC}_{\text {MÁX }}(5 \%$ prob.) & 46,94 & 13,69 & 25,6 & 4,29 & 2,49 & 29,09 & 76,89 & \\
\hline IC MÍN (5\% prob.) & 34,13 & 3,49 & 19,3 & 3,21 & 2,09 & 17,34 & 64,61 & \\
\hline
\end{tabular}


O resíduo de papel reciclado foi doado pela Cia. Volta Grande (CVG). Após acondicionamento em ambiente externo, foram realizadas atividades para homogeneizar a granulometria e o teor de umidade do resíduo utilizado no experimento. A granulometria do resíduo foi avaliada pela escala de Wentworth, tendo sido homogeneizada com o uso de duas peneiras de metal sobrepostas. A inferior, com abertura quadrangular de $3,0 \mathrm{~cm}$ e a superior com abertura circular com raio de $1,5 \mathrm{~cm}$. O resíduo foi "esfarelado" manualmente pela fricção sobre as grelhas, formando agregados com diâmetro de cerca de $15 \mathrm{~mm}$ e formato pouco uniforme. O material foi armazenado e acondicionado no laboratório de proteção florestal da Unicentro até a sua utilização.

No momento da implantação do experimento, foram separadas quatro amostras de $500 \mathrm{~g}$ do resíduo granulado, para determinação do teor de umidade. Após pesagem, o material úmido foi seco em estufa $\left(100^{\circ} \mathrm{C}\right)$. Foram realizadas pesagens diárias até a estabilização do peso seco do resíduo. $\mathrm{O}$ teor de umidade gravimétrica estabilizou-se em $60,7 \pm 3,7 \%$ após dez dias de avaliações.

\section{Tratamentos}

Em todos os tratamentos, as mudas utilizadas eram homogêneas e do clone " 2864 " de Eucalyptus saligna Sm., com três meses de idade, provenientes do viveiro da empresa Klabin. Os tratamentos consistiram em doses crescentes de resíduo misturados com o solo com o uso de uma betoneira de construção civil. Foram testadas cinco doses de resíduos, caracterizadas como 0,0 (v/v), 12,5 $(\mathrm{v} / \mathrm{v}), 25(\mathrm{v} / \mathrm{v}), 50(\mathrm{v} / \mathrm{v})$ e $75(\mathrm{v} / \mathrm{v})$, em que v/v significa porcentagem do volume do vaso. As misturas foram acondicionadas em vasos de polipropileno de $8,5 \mathrm{~L}$. O plantio das mudas foi feito simulando a implantação florestal, uma vez que os vasos foram posicionados em campo em uma área plana e com espaçamento de $2 \times 2 \mathrm{~m}$.

O segundo fator avaliado foi o efeito da adubação em cobertura, comumente utilizada na silvicultura do eucalipto. Foi utilizado com NPK na proporção 4-14-8. Essa adubação foi realizada trinta dias após o plantio, conforme cronograma usual de implantação florestal. Foi aplicado uniformemente o equivalente a $50 \mathrm{~g}$ de adubo por vaso, na superfície do solo.

\section{Nutrição florestal}

Aos 120 dias após a implantação, foram feitas amostragens foliares e de raízes para avaliar a resposta dos tratamentos para os teores de macronutrientes. Foram amostrados o sistema radicular total e um ramo por planta, no total de vinte plantas por tratamento. As folhas foram selecionadas levando-se em conta a face norte e a parte mediana das plantas. Folhas muito jovens ou velhas não foram amostradas.

Os ramos e raízes coletados foram lavados em bandejas com água deionizada e colocados em papel-toalha para secagem ao ar. Logo após, foram secos em estufa com temperatura de $70{ }^{\circ} \mathrm{C}$. Dessa forma, as folhas e raízes secas foram moídas e guardadas em recipientes de vidro, até a execução de análises laboratoriais para macro e micronutrientes, realizadas no laboratório de fertilidade do solo e de biogeoquímica da Universidade Federal do Paraná.

Foram realizados exames de rotina para $\mathrm{N}, \mathrm{P}, \mathrm{K}^{+}, \mathrm{Ca}^{2+}, \mathrm{Mg}^{2+}$, segundo recomendações de Martins e Reissmann (2007). Foi utilizado o delineamento inteiramente casualizado, com dois fatores (dose e adubação) e três repetições, totalizando dezoito amostras de folhas e dezoito de raízes por nutriente. Os dados tiveram distribuição normal e foram analisados pela Anova. As médias foram comparadas pelo teste de Tukey ( $\mathrm{p}<0,05$ ), usando-se o software Assistat (de SILVA; AZEVEDO, 2002).

Os teores de macronutrientes foram demonstrados pela elaboração de gráficos de tendência no Excel, em modelos de regressão polinomial cúbica. Os resultados que não tiveram diferença significativa, nem efeito de interação, foram elaborados com as médias gerais. Para os resultados com diferenças significativas, estas foram evidenciadas nas curvas de regressão, e o efeito da interação entre adubação e dose do resíduo foi verificado ao se analisarem os pontos de interseção entre as curvas ajustadas.

\section{Biomassa e eficiência de utilização de nutrientes (EUN)}

Os dados foram transformados para o parâmetro EUN (g biomassa / g nutriente) a partir das médias gerais obtidas da biomassa de raízes e sem considerar as diferentes dosagens de lodo de papel reciclado, tornando possível demonstrar quais macronutrientes contribuíram no desenvolvimento das plantas do experimento. 
Para tanto, aos 120 dias da implantação, foram coletadas as raízes de vinte plantas de cada tratamento, para quantificação da sua biomassa total. As raízes foram acondicionadas em sacos de papelão e levadas para o laboratório de polpa e papel da UFPR, onde foram secas em estufa na temperatura de $60^{\circ} \mathrm{C}$. Logo após, foram pesadas em balança com precisão de uma casa decimal.

$\mathrm{Na}$ análise de biomassa de raízes, foram utilizadas vinte plantas por tratamento (repetições), sendo 10 tratamentos (5 doses de lodo com adubação e 5 doses sem adubação), totalizando 200 amostras. Os dados referentes a cada variável não precisaram ser transformados e foram analisados pela Anova, e as médias comparadas pelo teste de Tukey $(\mathrm{p}<0,05)$.

\section{RESULTADOS E DISCUSSÃO}

\section{Eficiência nutricional dos macronutrientes nos tratamentos}

Ao se agruparem os dados dos teores nutricionais dos macronutrientes com as médias gerais de cada elemento, desconsiderando as diferentes doses de resíduo utilizadas, percebem-se tendências distintas entre as concentrações das raízes e das folhas. A adubação em cobertura pouco influenciou nessas tendências, com as sequências tendo sido semelhantes entre raízes com e sem adubação. As sequências também foram idênticas para as folhas com e sem adubação NPK.

Para as raízes, o Ca foi o elemento com maior concentração, devido ao uso experimental do lodo de papel reciclado. A ordem decrescente completa dos teores dos macronutrientes nas raízes foi a seguinte: $\mathrm{Ca}>\mathrm{N}, \mathrm{K}>\mathrm{Mg}>\mathrm{P}$.

Macedo et al. (1996) concluíram que as espécies de eucalipto apresentam concentrações foliares decrescentes para os seguintes macronutrientes: $\mathrm{Ca}>\mathrm{K}>\mathrm{Mg}>\mathrm{P}$, ou seja, os dados desses autores foram semelhantes aos resultados verificados nas raízes das plantas aqui amostradas. Para as folhas, os grupos com e sem adubação apresentaram os teores nutricionais decrescentes na seguinte ordem: $\mathrm{N}>\mathrm{K}>\mathrm{Ca}>$ $\mathrm{Mg}>\mathrm{P}$.

Santana et al. (2002) afirmam que a eficiência de utilização de nutrientes (EUN) em eucalipto (E. grandis e E. saligna) decresceu na seguinte ordem: $\mathrm{P}>\mathrm{Mg}>\mathrm{K}>\mathrm{N}>\mathrm{Ca}$, sendo essa a mesma tendência observada por Santana et al. (2000). Ao serem os mesmos dados transpostos para o parâmetro EUN (g biomassa / g nutriente), a partir das médias gerais obtidas da biomassa de raízes, é possível elaborar a tabela 2, que demonstra quais os macronutrientes contribuíram no desenvolvimento das plantas do experimento.

Tabela 2. Eficiência de utilização de macronutrientes (EUN) nas raízes.

Table 2. Efficiency of macronutrients utilization in the roots.

\begin{tabular}{lccc}
\hline EUN & Com adubação & Sem adubação & EUN \\
\hline 0,58 & $\mathrm{Ca}$ & $\mathrm{Ca}$ & 0,25 \\
1,11 & $\mathrm{~N}$ & $\mathrm{~K}$ & 0,66 \\
1,19 & $\mathrm{~K}$ & $\mathrm{~N}$ & 0,97 \\
4,23 & $\mathrm{Mg}$ & $\mathrm{Mg}$ & 2,38 \\
4,34 & $\mathrm{P}$ & $\mathrm{P}$ & 3,44 \\
\hline
\end{tabular}

Quanto maior a EUN, que é adimensional, maior a biomassa vegetal formada para a mesma quantidade de nutriente. Ou seja, quanto maior a EUN, mais eficiente é o nutriente. O P foi o elemento com maior EUN, seguido do Mg. Assim, evidencia-se a importância desse macronutriente. A sequência de EUN completa para as raízes foi $\mathrm{P}>\mathrm{Mg}>\mathrm{K}, \mathrm{N}>\mathrm{Ca}$. Esses dados foram semelhantes aos apresentados por Santana et al. (2000) e Santana et al. (2002).

\section{$\mathbf{N}$}

Para o grupo de plantas com adubação NPK, não houve efeito significativo do aumento das doses de resíduo na absorção no $\mathrm{N}$ pelas raízes $(\mathrm{F}=1,79, \mathrm{p}>0,05)$. Em termos absolutos, os teores variaram entre 2,56 g. $\mathrm{kg}^{-1}$ (dose $75 \mathrm{v} / \mathrm{v}$ sem adubação) e $9,25 \mathrm{~g} \cdot \mathrm{kg}^{-1}$ (dose $75 \mathrm{v} / \mathrm{v} \mathrm{com} \mathrm{adubação).} \mathrm{Os}$ teores de $\mathrm{N}$ encontrados nas raízes também não diferiram estatisticamente em função da interação $(\mathrm{F}=1,14, \mathrm{p}>0,05)$. A diferença estatística foi verificada apenas em função da adubação em cobertura $(\mathrm{F}=8,79, \mathrm{p}<0,05)$. 
As equações ajustadas tanto para o grupo com adubação quanto para o sem adubação levam a crer que as doses crescentes do lodo de papel reciclado contribuíram para a absorção de $\mathrm{N}$ para as folhas nas doses entre $25 \mathrm{v} / \mathrm{v}$ e $50 \mathrm{v} / \mathrm{v}$. A partir desta, a absorção tendeu a ser prejudicada, conforme a resposta verificada na dose $75 \mathrm{v} / \mathrm{v}$.

Para o $\mathrm{N}$ foliar, houve efeito significativo da adubação $(\mathrm{F}=61,06, \mathrm{p}<0,01)$, da dose de resíduo $(\mathrm{F}=49,58, \mathrm{p}<0,01)$ e da interação $(\mathrm{F}=9,22, \mathrm{p}<0,01)$. A adubação em cobertura resultou em maiores teores de $\mathrm{N}$ para todas as doses de resíduo. Nesse grupo, os valores variaram entre $12,87 \mathrm{~g}^{\mathrm{kg}} \mathrm{kg}^{-1} \mathrm{e}$ 29,20 g.kg ${ }^{-1}$, na dose $25 \mathrm{v} / \mathrm{v}$.

Malavolta et al. (1997) mencionam que o teor foliar de $\mathrm{N}$ adequado para a cultura do eucalipto está entre 1,40 e 1,60 g. $\mathrm{kg}^{-1}$. Os valores aqui encontrados oscilaram entre sete e trinta $\mathrm{g} . \mathrm{kg}^{-1}$, muito superiores a essa recomendação. Também ficou nítido que o $\mathrm{N}$ estava presente em maior quantidade na parte aérea das plantas e não nas raízes.

Barreto (2008) verificou, com o resíduo de celulose e papel, que a concentração de $\mathrm{N}$ na folha de eucalipto diminuiu com o aumento da dose. A maior dose daquele composto $\left(18,6\right.$ t.ha $\left.^{-1}\right)$ não elevou a concentração de $\mathrm{N}$ nas folhas em relação à sua não aplicação, apresentando uma concentração média nas folhas de $5,18 \mathrm{~g} \cdot \mathrm{kg}^{-1}$ na maior dose.

Em termos absolutos, a concentração foliar de $5,18 \mathrm{~g} \cdot \mathrm{kg}^{-1}$ obtida por Barreto (2008) na maior dose de resíduo daquela pesquisa é próxima ao resultado de $7,65 \mathrm{~g}^{-\mathrm{kg}^{-1}}$ obtido na dose $75 \mathrm{v} / \mathrm{v}$ sem adubação, porém muito inferior ao valor de $22,65 \mathrm{~g} \cdot \mathrm{kg}^{-1}$ obtido na dose $75 \mathrm{v} / \mathrm{v}$ com adubação.

Rocha et al. (2004) mencionam que os macronutrientes foliares se diluem nas folhas, e com o tempo os teores vão apresentando resultados menores, em decorrência de uma ou mais destas causas: (i) diluição das quantidades nutricionais numa maior biomassa foliar; (ii) diminuição da demanda nutricional pela árvore, graças ao fechamento de copas e à queda do metabolismo foliar, ocasionada por maior auto e intercompetição foliar por luz e água, sobretudo nas porções mais velhas das copas; e (iii) retranslocação interna de nutrientes.

Para Rodrigues (2004), o N e o fósforo foliares apresentam forte correlação negativa com o crescimento vegetal, indicando que os menores teores nas acículas coincidiram com os maiores valores de produção. Isso foi explicado pelo efeito de diluição do $\mathrm{N}$ e do fósforo nas acículas, conforme as árvores aumentaram de tamanho (ibid.). É provável que as maiores quantidades de $\mathrm{N}$ detectadas nos tratamentos com maior quantidade de lodo de papel reciclado estejam associadas a esse efeito da diluição, uma vez que os maiores teores foram verificados nas plantas que menos cresceram. Ferreira et al. (2007) recomendam estudos no sentido de definir as doses adequadas de $\mathrm{N}$ e fósforo como fertilização mineral em conjunto com o uso do resíduo de celulose, para utilização como substrato para a produção de mudas de eucalipto.

$\mathbf{P}$

As curvas de tendência ajustadas para os teores de $\mathrm{P}$ nas raízes sugerem que, para o grupo sem adubação em cobertura, quanto maior a dose de resíduo, maior a absorção de $\mathrm{P}$ via raízes. Reitera-se que havia a presença de $\mathrm{P}$ no solo experimental, em função dos teores encontrados naturalmente $\left(13,69 \mathrm{mg} \cdot \mathrm{dm}^{-3}\right)$. A Anova detectou diferenças em função das doses de resíduo $(\mathrm{F}=3,66, \mathrm{p}<0,05)$ e da adubação de cobertura $(\mathrm{F}=22,14, \mathrm{p}<0,01)$, mas sem interação entre elas $(\mathrm{F}=2,29)$.

Segundo Barros et al. (1982), os níveis de P necessários para o crescimento inicial de mudas de eucalipto são elevados, demonstrando que, no estádio muito jovem (menos de seis meses pós-plantio), o eucalipto é pouco efetivo na absorção desse elemento, principalmente em razão do sistema radicular pouco desenvolvido. A presença do P nas raízes no tratamento $12,5 \mathrm{v} / \mathrm{v}$ com adubação NPK $\left(2,07 \mathrm{~g}^{\mathrm{kg}} \mathrm{kg}^{-1}\right)$ foi significativamente superior a todos os outros tratamentos. No entanto, o polinômio ajustado e os resultados do teste de comparação de médias sugerem que nesse grupo as doses crescentes de resíduo não influenciaram a absorção do $\mathrm{P}$ pelas raízes. Ou seja, no experimento a adubação de cobertura foi suficiente para conferir teores de $\mathrm{P}$ nas raízes superiores aos dos outros tratamentos, que também dispunham de outras fontes de $\mathrm{P}$.

A figura 1 demonstra os resultados para $\mathrm{N}, \mathrm{P}$ e $\mathrm{K}$ em folhas e raízes.

FLORESTA, Curitiba, PR, v. 45, n. 2, p. 261 - 272, abr. / jun. 2015.

Faria, A. B. de C.; Angelo, A. C.; Auer, C. G.

ISSN eletrônico 1982-4688 / ISSN impresso 0015-3826

DOI: $10.5380 /$ rf.v45i2.26506 

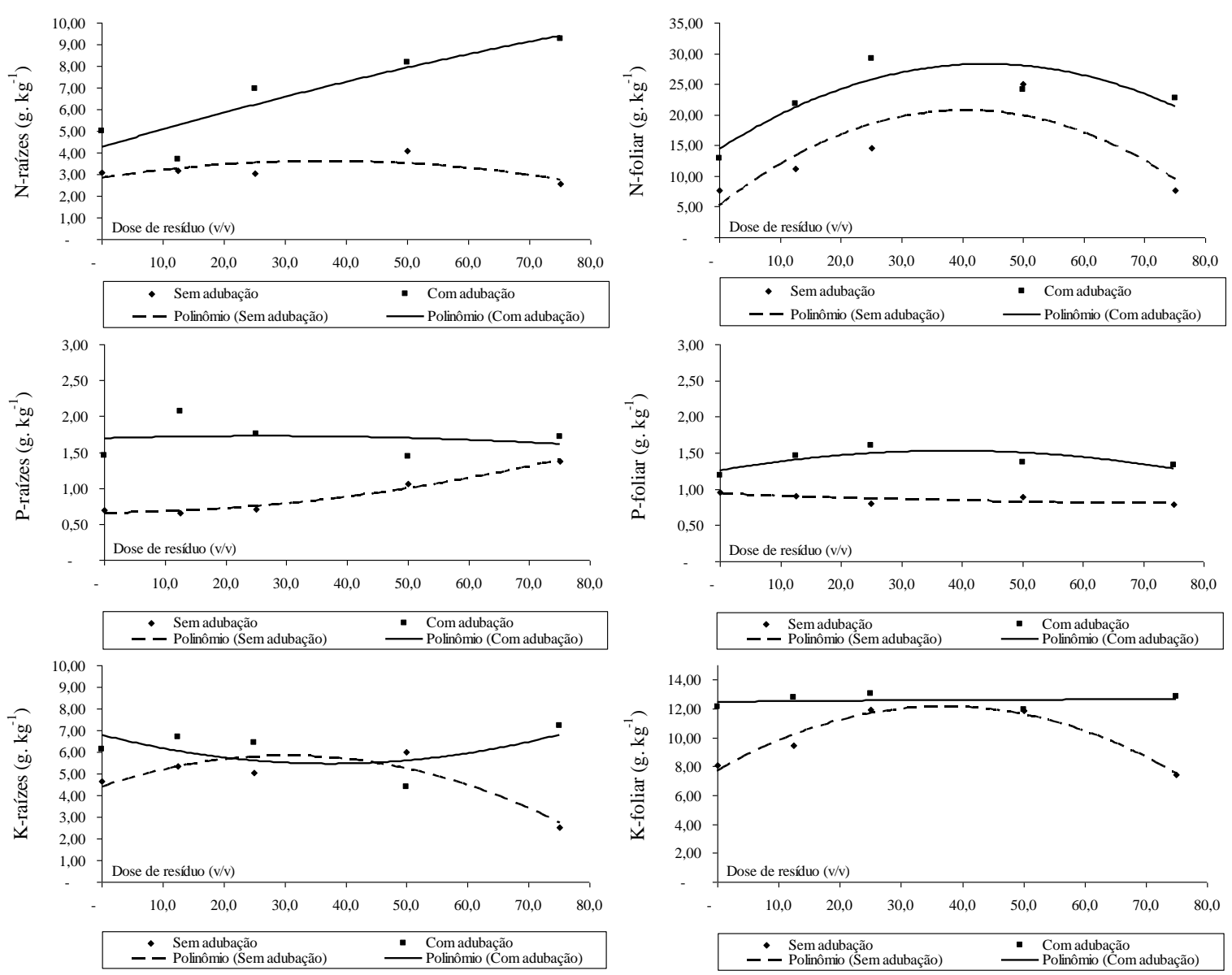

Figura 1. Resultados para N, P e K analisados nas folhas e raízes.

Figure 1. Results for N, P and $\mathrm{K}$ analyzed in leaves and roots.

Malavolta et al. (1997) definiram que, para a obtenção de altas produtividades de Eucalyptus grandis, os teores de $\mathrm{P}$ devam permanecer entre 1,3 e 1,4 g.kg-1 Há evidências, portanto, de que o lodo de papel reciclado não interferiu na absorção do $\mathrm{P}$ para as folhas.

Em relação ao $\mathrm{P}$ foliar para o grupo sem adubação em cobertura, verificou-se que os teores permaneceram abaixo do grupo com adubação, tendo oscilado entre $0,79 \mathrm{~g} \cdot \mathrm{kg}^{-1}($ dose $75 \mathrm{v} / \mathrm{v})$ e $0,96 \mathrm{~g}^{-\mathrm{kg}^{-1}}$ (testemunha). $\mathrm{O}$ teste de comparação de médias não indicou nenhuma tendência definida nesse grupo.

Rodrigues (2004) argumenta que a obtenção de elevados teores de $\mathrm{P}$ em acículas de pínus pode estar associada ao efeito da concentração desses nutrientes em uma menor massa vegetal, porque em seus resultados a testemunha que cresceu menos obteve maiores valores para esse macronutriente, quando comparada às plantas que receberam aplicação de resíduo de indústria de papel, e que produziram mais.

Com base nos resultados dos teores de $\mathrm{P}$ foliares e radiculares, pode-se dizer que a absorção desse nutriente não foi prejudicada pelas doses crescentes de resíduo.

\section{$\mathbf{K}$}

A Anova detectou diferenças significativas para $\mathrm{o} K$ das raízes em função da adubação $(\mathrm{F}=76,41, \mathrm{p}<0,01)$, das doses $(\mathrm{F}=72,50, \mathrm{p}<0,01)$ e da interação $(\mathrm{F}=37,16, \mathrm{p}<0,01)$. As doses de resíduo nos tratamentos do grupo sem adubação em cobertura mostraram uma tendência de redução do $\mathrm{K}$ com o aumento das doses. A dose $75 \mathrm{v} / \mathrm{v}$ apresentou o menor valor $\left(2,51 \mathrm{~g} \cdot \mathrm{kg}^{-1}\right)$.

No entanto, o grupo de plantas com adubação em cobertura apresentou teores de $\mathrm{K}^{+}$radicular aparentemente crescentes em função do aumento das doses de resíduo. As doses testemunha, 12,5 v/v e 
$25 \mathrm{v} / \mathrm{v}$ apresentaram $\mathrm{K}^{+}$radicular na casa dos $6,0 \mathrm{~g} \cdot \mathrm{kg}^{-1}$. A dose $75 \mathrm{v} / \mathrm{v}$ apresentou o teor de 7,23 g.kg-1, tendo sido o maior valor observado entre tratamentos.

Gonçalves e Moro (1995) verificaram que a aplicação da cinza de caldeira proporcionou absorção muito maior de $\mathrm{K}^{+} \mathrm{e} \mathrm{Ca}^{2+}$, nutrientes presentes em maior abundância na cinza. Esses nutrientes mostraram efeito sinérgico sobre a absorção de outros nutrientes contidos em pequena quantidade na cinza, e.g. o N (ibid.). Com o pó de basalto e esterco equino, Knapik e Ângelo (2007) constataram que a maior absorção de $\mathrm{Ca}^{2+}$ pode ter influenciado na menor absorção de $\mathrm{K}^{+}$, mas não obtiveram diferenças significativas nas diferentes adubações. Por outro lado, Rocha et al. (2004) atribuíram a diminuição dos teores de $\mathrm{K}^{+}$até os 32 meses de idade de $E$. grandis, para todos os tratamentos que receberam o lodo de esgoto, à diluição desse nutriente na planta ou à absorção antagônica do $\mathrm{Ca}^{2+}$ em relação ao $\mathrm{K}^{+}$. Com o uso de lama de cal, Stappe e Balloni (1988) constataram tendência de elevação do teor de Ca das folhas e diminuição dos de $\mathrm{K}$ (e Mg).

Os resultados não forneceram dados para se concluir sobre a capacidade do $\mathrm{Ca}^{2+}$ de impedir o transporte interno do $\mathrm{K}^{+}$para diferentes partes da planta. Até o limite da dose $12,5 \mathrm{v} / \mathrm{v}$, o risco de competição de $\mathrm{Ca}^{2+}$ com o $\mathrm{K}^{+}$não foi perceptível.

Para o $\mathrm{K}$ foliar, houve efeito significativo da adubação $(\mathrm{F}=29,25, \mathrm{p}<0,01)$, da dose de resíduo $(\mathrm{F}=52,98, \mathrm{p}<0,01)$ e da interação $(\mathrm{F}=4,57, \mathrm{p}<0,01)$. Para o grupo com adubação em cobertura, no entanto, os resultados do teste de Tukey não indicaram tendências em função das diferentes doses do resíduo.

Tais diferenças aconteceram no grupo sem adubação. A figura 1 sugere que as doses crescentes do lodo favoreceram a absorção de $\mathrm{K}^{+}$para as folhas até o limite da dose $50 \mathrm{v} / \mathrm{v}$. É provável que a redução do teor foliar de $\mathrm{K}$ na dose $75 \mathrm{v} / \mathrm{v}$ do grupo sem adubação se deva ao reflexo do que aconteceu nas raízes daquele grupo de plantas, que manifestou a mesma tendência.

Malavolta et al. (1997) definiram que, para a obtenção de altas produtividades de Eucalyptus grandis, os teores de $\mathrm{K}^{+}$devam permanecer entre 9 e $10 \mathrm{~g} \cdot \mathrm{kg}^{-1}$. Esses dados são próximos aos encontrados nos tratamentos com NPK, com plantas de apenas quatro meses de idade.

Os próximos estudos com o uso do lodo de papel reciclado na silvicultura do eucalipto devem levar em consideração outras fontes suplementares de K para as plantas, especialmente na implantação florestal.

Ca

A figura 2 indica que, nas raízes, o aumento dos teores de $\mathrm{Ca}^{2+}$ no grupo sem adubação ocorreu exponencialmente com o aumento das doses de resíduo $(\mathrm{F}=456,42, \mathrm{p}<0,01)$. Esse é um forte indicativo de que o $\mathrm{Ca}^{2+}$ do resíduo estava prontamente assimilável para absorção radicular de $E$. saligna. A dose $75 \mathrm{v} / \mathrm{v}$ resultou em teor de $28,43 \mathrm{~g} . \mathrm{kg}^{-1}$, tendo sido o maior resultado entre os tratamentos.

Estatisticamente, a adubação em cobertura não influenciou significativamente a disponibilização de Ca pelas raízes $(\mathrm{F}=0,32)$. Entretanto, foi detectada uma forte interação entre a adubação e o lodo de papel reciclado $(\mathrm{F}=83,29, \mathrm{p}<0,01)$. As plantas do grupo com NPK absorveram mais Ca com o aumento das doses de resíduo, mas somente até o limite de $19,75 \mathrm{~g} \cdot \mathrm{kg}^{-1}$, tendo-se estabilizado a $17,91 \mathrm{~g} \cdot \mathrm{kg}^{-1}$ (doses $50 \mathrm{v} / \mathrm{v}$ e $75 \mathrm{v} / \mathrm{v})$.

A figura 2 demonstra os resultados para $\mathrm{Ca}$ e $\mathrm{Mg}$ em folhas e raízes.
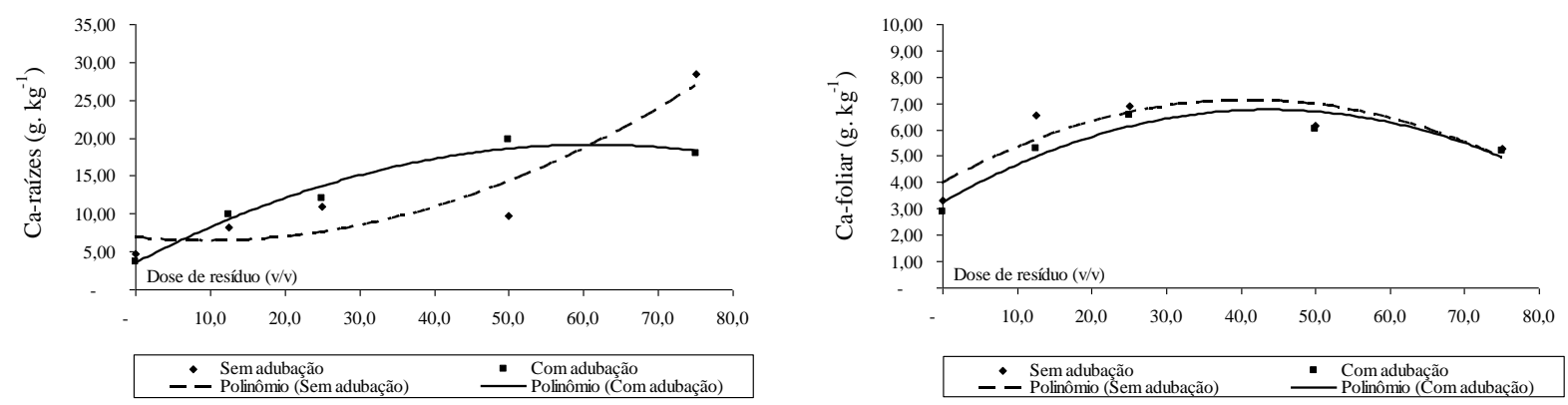

FLORESTA, Curitiba, PR, v. 45, n. 2, p. 261 - 272, abr. / jun. 2015.

Faria, A. B. de C.; Angelo, A. C.; Auer, C. G.

ISSN eletrônico 1982-4688 / ISSN impresso 0015-3826

DOI: $10.5380 /$ rf.v45i2.26506 

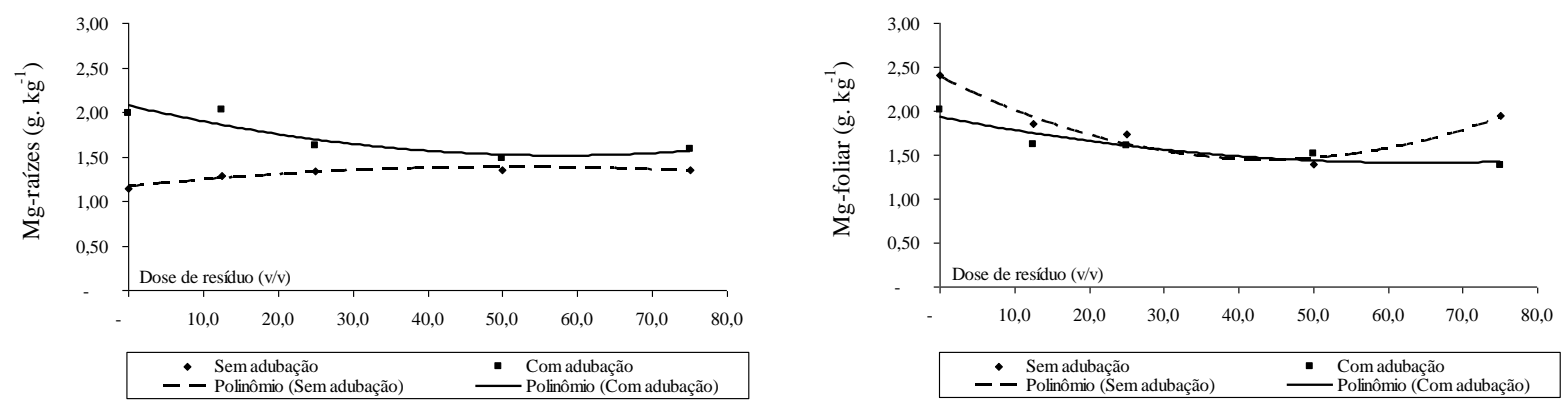

Figura 2. Resultados para $\mathrm{Ca}$ e $\mathrm{Mg}$ analisados nas folhas e raízes.

Figure 2. Results for $\mathrm{Ca}$ and $\mathrm{Mg}$ analyzed in leaves and roots.

O favorecimento da absorção de $\mathrm{Ca}^{2+}$ pelas raízes foi decorrente da presença abundante desse elemento no solo, tendo influenciado negativamente no crescimento em biomassa das plantas.

O solo experimental apresentava naturalmente $3,62 \mathrm{cmol}_{\mathrm{c}} \cdot \mathrm{dm}^{-3} \mathrm{de} \mathrm{Ca}$. A forte presença de Ca no resíduo sugeria que haveria uma maior translocação desse nutriente nas folhas de E. saligna. Os resultados para o $\mathrm{Ca}^{2+}$ foliar indicaram diferenças em função da adubação $(\mathrm{F}=4,39, \mathrm{p}<0,05)$ e das doses principalmente $(\mathrm{F}=74,05, \mathrm{p}<0,01)$, mas sem interação $(\mathrm{F}=1,21, \mathrm{p}<0,01)$.

Os teores foliares de $\mathrm{Ca}^{2+}$ aumentaram até a dose $50 \mathrm{v} / \mathrm{v}$, tendo diminuído na dose $75 \mathrm{v} / \mathrm{v}$. Esse comportamento foi verificado tanto para o grupo com quanto para o sem adubação em cobertura. Curiosamente, o grupo sem adubação mostrou teores foliares de Ca levemente superiores aos do grupo com NPK.

Segundo Malavolta (1980), o Ca é um elemento imóvel nas plantas e não sofre os efeitos de diluição com o crescimento dos tecidos vegetais, e o maior acúmulo de $\mathrm{Ca}$ no lenho pode estar relacionado com a imobilidade do Ca na árvore. Essas informações dão a entender que o excesso do Ca nas plantas do experimento dificultou o seu crescimento vegetativo.

Malavolta et al. (1997) mencionam os teores foliares de Ca de 0,80 a 1,20 g. $\mathrm{kg}^{-1}$ como adequados para a cultura do eucalipto. Sgarbi et al. (1999) apresentaram para o híbrido E. grandis $x$ E. urophylla a concentração de $\mathrm{Ca}^{2+}$ nas folhas novas e velhas de $2,4 \mathrm{~g}^{\mathrm{kg}} \mathrm{kg}^{-1}$ e $2,7 \mathrm{~g} \cdot \mathrm{kg}^{-1}$, não tendo apresentado redução no crescimento e na produção de matéria seca. Os dados aqui encontrados foram nitidamente superiores a esses parâmetros, mesmo nas testemunhas, uma vez que, além do $\mathrm{Ca}^{2+}$ fornecido pelo resíduo, também havia Ca presente no solo. Assim, tem-se um indicativo de que o excesso de Ca nas plantas prejudicou o seu crescimento, haja vista a expectativa de arranque exponencial de crescimento em diâmetro e altura na implantação do eucalipto, especialmente nas épocas quentes de verão, como feito neste trabalho.

Barreto (2008) constatou o aumento das concentrações do Ca nas folhas de eucalipto, devido às grandes quantidades de $\mathrm{Ca}^{2+}$ na composição do resíduo de indústria de celulose. De forma semelhante, Knapik e Ângelo (2007) mencionam que a presença de $\mathrm{Ca}^{2+}$ nas folhas de mudas de pessegueiro-bravo produzidas no tratamento com pó de basalto foi cerca de duas vezes maior que na testemunha, e que a adubação com esterco equino também propiciou mudas com maiores quantidades de $\mathrm{Ca}^{2+}$.

Os dados aqui apresentados indicam que as plantas que mais cresceram (dose $0,0 \mathrm{v} / \mathrm{v}$ com adubação) tinham 2,88 g. $\mathrm{kg}^{-1} \mathrm{de} \mathrm{Ca}{ }^{2+}$ nas folhas (valor próximo ao encontrado por Sgarbi et al., 1999) e não apresentaram os maiores teores desse nutriente.

\section{Mg}

Nas raízes, o teor de $\mathrm{Mg}^{2+}$ foi influenciado apenas pela adubação em cobertura $(\mathrm{F}=7,10$, $\mathrm{p}<0,05$ ), que apresentou plantas com teores entre $1,48 \mathrm{~g}_{\mathrm{kg}} \mathrm{kg}^{-1}$ e $2,02 \mathrm{~g}_{\mathrm{gg}} \mathrm{kg}^{-1}$, um pouco superiores aos valores do grupo de plantas sem adubação.

$\mathrm{O}$ solo experimental apresentava $2,52 \mathrm{cmol}_{\mathrm{c}} \cdot \mathrm{dm}^{-3} \mathrm{de} \mathrm{Mg}$. Apesar de não ter apresentado diferenças significativas, os teores de $\mathrm{Mg}$ nas folhas foram um pouco superiores no grupo de plantas sem adubação. Para esse nutriente, não houve diferenças em relação à adubação $(F=2,08, p>0,05)$, à dose de resíduo $(\mathrm{F}=2,50, \mathrm{p}>0,05)$ e à interação $(\mathrm{F}=0,53, \mathrm{p}>0,05)$. 
O híbrido E. grandis x E. urophylla avaliado por Sgarbi et al. (1999) apresentou concentração de $\mathrm{Mg}^{2+}$ nas folhas novas e velhas de $1,8 \mathrm{~g} \cdot \mathrm{kg}^{-1} \mathrm{e} 1,5 \mathrm{~g} \cdot \mathrm{kg}^{-1}$, não tendo apresentado redução no crescimento e na produção de matéria seca. Esses dados são parecidos aos aqui encontrados.

A concentração foliar de $\mathrm{Mg}^{2+}$ oscilou entre 1,0 e 2,0 g. $\mathrm{kg}^{-1}$ para todos os tratamentos. Porém Malavolta et al. (1997) definiram que para a obtenção de altas produtividades de Eucalyptus grandis os teores de $\mathrm{Mg}^{2+}$ devam permanecer entre 2,5 e $3 \mathrm{~g} \cdot \mathrm{kg}^{-1}$, valores superiores aos aqui descritos.

O resíduo de indústria de celulose testado por Barreto (2008) influenciou na concentração de $\mathrm{Mg}^{2+}$ nas folhas, porém diminuíram com o aumento das doses de composto. Os resíduos usados apresentavam grandes quantidades de $\mathrm{Ca}^{2+}$ e pequenas de $\mathrm{Mg}^{2+}$. Trigueiro (2006) considera que o aumento da concentração de $\mathrm{Ca}$ na solução do solo tenha prejudicado a absorção do $\mathrm{Mg}$, para eucalipto.

Os resultados aqui encontrados não evidenciaram a queda dos teores de $\mathrm{Mg}^{2+}$ com o aumento das doses de lodo de papel reciclado, rico em Ca. Rodrigues (2004) verificou que o Pinus taeda chegou a acumular 219\% a mais de $\mathrm{Ca}$ e $372 \%$ a mais de $\mathrm{Mg}$ do que a testemunha que não recebeu a aplicação de resíduo de indústria de papel, o que indica que o $\mathrm{Ca}^{2+}$ e o $\mathrm{Mg}^{2+}$ não foram concorrentes.

Segundo Malavolta et al. (1997), a absorção de $\mathrm{H}_{2} \mathrm{PO}_{4}$ é máxima na presença do $\mathrm{Mg}^{2+}$, pois este possui a função de carregador de $\mathrm{P}$, com participação na ativação de ATPases da membrana implicadas na absorção iônica. Os dados não permitiram constatar isso, pois não houve diferenças significativas. Esse comportamento também era esperado no estudo de Knapik e Ângelo (2007), que obtiveram altas concentrações de $\mathrm{Mg}^{2+}$ (5,0 g. $\left.\mathrm{kg}^{-1}\right)$ com o uso de pó de basalto nas mudas de pessegueiro-bravo (Prunus sellowii Koehne).

\section{CONCLUSÕES}

Os efeitos do lodo de papel reciclado sobre os macronutrientes em folhas e raízes das plantas foram os seguintes:

- O lodo de papel reciclado não interfere na disponibilização do P;

- O lodo de papel reciclado não é uma fonte de $\mathrm{N}, \mathrm{K}$ e Mg para as plantas;

- O resíduo é uma fonte de Ca para o desenvolvimento vegetal.

\section{REFERÊNCIAS}

ANDRADE, G. C.; SILVA, H. D.; BELLOTE, A. F. J.; FERREIRA, C. A. Efeitos da adubação fosfatada e da aplicação de resíduo de celulose no crescimento de Eucalyptus dunnii. Boletim de Pesquisas Florestais, Colombo, n. 47, p. 43 - 54, 2003.

ANDRADE, C. A.; OLIVEIRA, C.; CERRI, C. C. Qualidade da matéria orgânica e estoques de carbono e nitrogênio em Latossolo tratado com biossólido e cultivado com eucalipto. Revista Brasileira de Ciência do Solo, Viçosa, v. 29, n. 5, p. 803 - 816, 2005.

BALBINOT JÚNIOR, A. A.; TORRES, A. N. L.; FONSECA, J. A.; TEIXEIRA, J. R.; NESI, C. N. Alteração em características químicas de um solo ácido pela aplicação de calcário e resíduos de reciclagem de papel. Revista de Ciências Agroveterinárias, Lages, v. 5, n. 1, p. 16 - 25, 2006 a.

BARRETO, V. C. M. Resíduos de indústria de celulose e papel na fertilidade do solo e no desenvolvimento de eucalipto. $64 \mathrm{f}$. Tese (Doutorado em Produção Vegetal) - Faculdade de Ciências Agrárias e Veterinárias, Universidade Estadual Paulista, Jaboticabal, 2008.

BARROS, N. F.; NOVAIS, R. F.; NEVES, J. C. L.; GOMES, J. M. Interpretação de análises químicas de solo para o crescimento de Eucalyptus spp. Revista Árvore, Viçosa, v. 6, n. 1, p. 38 - 44, 1982.

COSTA, E. R. O.; RIZZI, N. E.; SILVA, H. D.; MAEDA, S.; LAVORANTI, O. J. Alterações químicas do solo após aplicação de biossólidos de estação de tratamento de efluentes de fábrica de papel reciclado. Revista Floresta, Curitiba, v. 39, n. 1, p. 1 - 10, 2009.

FERREIRA, C. A.; SILVA, H. D.; ANDRADE, G. C. Efecto de la aplicación de ceniza de caldera y residuo de celulosa en el suelo y en el crecimiento de Eucalyptus grandis. Bosque, Valdivia, v. 16, n. 1, 
p. $95-100,1995$.

FERREIRA, C. S.; SOUSA, S. M.; COSTA, A. S. V. Utilização de resíduo de celulose associado a adubação com nitrogênio e fósforo na produção de mudas de E. grandis. Revista Brasileira de Biociências, Porto Alegre, v. 5, supl. 2, p. 942 - 944, 2007.

GALBIATTI, J. A.; LUI, J. J.; SABONARO, D. Z.; BUENO, L. F.; SILVA, V. L. Formação de mudas de eucalipto com utilização de lixo orgânico e níveis de irrigação calculados por dois métodos. Engenharia Agrícola, Jaboticabal, v. 27, n. 2, p. 445 - 455, 2007.

GONÇALVES, J. L. M.; MORO, L. Uso da cinza de biomassa florestal como fonte de nutrientes em povoamentos puros de Eucalyptus grandis. IPEF, Piracicaba, n. 48/49, p. 28 - 37, 1995.

KNAPIK, J. G.; ÂNGELO, A. C. Crescimento de mudas de Prunus sellowii Koehne em resposta a adubações com NPK e pó de basalto. Floresta, Curitiba, v. 37, n. 2, p. 257 - 264, 2007.

LIMA, C. G. R.; CARVALHO, M. P.; NARIMATSU, K. C. P.; SILVA, M. G. S.; QUEIROZ, H. A. Q. Atributos físico-químicos de um Latossolo do Cerrado brasileiro e sua relação com características dendrométricas do eucalipto. Revista Brasileira de Ciência do Solo, Viçosa, v. 34, n. 1, p. 163 - 173, 2010.

LUNARDI NETO, A.; ALBUQUERQUE, J. A.; ALMEIDA, J. A.; MAFRA, A. L.; MEDEIROS, J. C.; ALBERTON, A. Atributos físicos do solo em área de mineração de carvão influenciados pela correção da acidez, adubação orgânica e revegetação. Revista Brasileira de Ciência do Solo, Viçosa, v. 32, n. 4, p. 1379 - 1388, 2008.

MACEDO, R. L. G.; SOARES, R. V.; SOARES, A. R. Status nutricional de Eucalyptus na fase juvenil introduzidos na baixada cuiabana, MT. Cerne, Lavras, v. 2, p. 106 - 118, 1996.

MALAVOLTA, E. Elementos de nutrição mineral de plantas. São Paulo: Ceres, 1980. 251 p.

MALAVOLTA, E.; VITTI, G. C.; OLIVEIRA, S. A. Avaliação do estado nutricional das plantas: princípios e aplicações. 2. ed. Piracicaba: Potafos, 1997. 319 p.

MARTINS, A. P. L.; REISSMANN, C. B. Material vegetal e as rotinas laboratoriais nos procedimentos químico-analíticos. Scientia Agraria, Curitiba, v. 8, n. 1, p. 1 - 17, 2007.

ROCHA, G. N.; GONÇALVES, J. L. M.; MOURA, I. M. Mudanças da fertilidade do solo e crescimento de um povoamento de Eucalyptus grandis fertilizado com biossólido. Revista Brasileira de Ciência do Solo, Viçosa, v. 28, n. 4, p. 623 - 639, 2004.

RODRIGUES, C. M. Efeito da aplicação de resíduo da indústria de papel nos atributos químicos, físicos e biológicos do solo, na nutrição e biomassa de Pinus taeda L. 21 f. Dissertação (Mestrado em Agronomia) - Setor de Ciências Agrárias, Universidade Federal do Paraná, Curitiba, 2004.

SANTANA, R. C.; BARROS, N. F.; COMERFORD, N. B. Aboveground biomass, nutrient content, and nutrient use efficiency of eucalypt plantations growing in different sites in Brazil. New Zealand Journal of Forest Science. Scion, Nova Zelândia, v. 30, n. 1/2, p. 225 - 236, 2000.

SANTANA, R. C.; BARROS, N. F.; NEVES, J. C. L. Eficiência de utilização de nutrientes e sustentabilidade da produção em procedências de Eucalyptus grandis e Eucalyptus saligna em sítios florestais do estado de São Paulo. Revista Árvore, Viçosa, v. 26, n. 4, p. 447 - 457, 2002.

SGARBI, F.; SILVEIRA, R. L. V. A.; TAKAHASHI, E. N.; CAMARGO, M. A. F. Crescimento e produção de biomassa de clone de Eucalyptus grandis x Eucalyptus urophylla em condições de deficiência de macronutrientes, B e Zn. Scientia Forestalis, Piracicaba, v.31, n. 56, p. 69 - 82, dez. 1999.

STAPPE, J. L.; BALLONI, E. A. O uso de resíduos da indústria de celulose como insumos na produção florestal. IPEF, Piracicaba, n. 40, p. 33 - 37, 1988.

TRIGUEIRO, R. M. Efeitos de dregs e grits nos atributos de um Neossolo quartzarênico e na produção volumétrica de eucalipto. $73 \mathrm{f}$. Tese (Doutorado em Energia na Agricultura) - Faculdade de Ciências Agronômicas, Universidade Estadual Paulista, Botucatu, 2006. 
VALERI, S. V.; CORRADINI, L.; AGUIAR, I. B.; SOUZA, E. C. A.; BANZATTO, D. A. Efeitos do fósforo e calcário dolomítico no desenvolvimento inicial de Eucalyptus grandis Hill Ex Maiden plantado em um Regossolo. IPEF, Piracicaba, n. 29, p. 55 - 60, 1985.

FLORESTA, Curitiba, PR, v. 45, n. 2, p. 261 - 272, abr. / jun. 2015.

Faria, A. B. de C.; Angelo, A. C.; Auer, C. G.

ISSN eletrônico 1982-4688 / ISSN impresso 0015-3826 
FLORESTA, Curitiba, PR, v. 45, n. 2, p. 261 - 272, abr. / jun. 2015.

Faria, A. B. de C.; Angelo, A. C.; Auer, C. G. 